\title{
O savoir-faire das personagens libertinas
}

\author{
Mariana Teixeira Marques
}

Universidade Federal de São Paulo 

Em 1772, Antoine Léonard Thomas, membro da Academia Francesa, publica seu Ensaio sobre o caráter, os costumes e o espírito das mulheres nos diferentes séculos. A Correspondance littéraire, da qual Diderot era um dos redatores, se apressa em confirmar o ponto de vista que já havia sido alardeado a respeito do pobre Thomas. Trata-se de um sujeito afável, um homem de bem e, sem dúvida, grande acadêmico. Porém, "sofre de uma tara" (Badinter, 1991, p. 7) bastante limitadora para um suposto especialista em mulheres: é virgem. Para além da ironia da situação e da maledicência dos contemporâneos do autor do Ensaio - sem mesmo entrar na questão a respeito do valor do que Thomas escreveu -, vale a pena retomar a argumentação que essa publicação proporcionou ao autor das Jóias indiscretas.

Bem ou mal, o tal Ensaio sobre as mulheres serviu de mote para que Diderot colocasse no papel suas reflexões a respeito de uma indagação que não parou de inquietar curiosos desde então: afinal de contas, o que define as mulheres? A resposta de Thomas parece em certa medida insatisfatória e Diderot o acusa, vejam só, de uma "imparcialidade e sabedoria" (Diderot, apud Badinter, 1991, p. 119). incompatíveis com o tema tratado. Para o nosso filósofo, o ensaio é enfraquecido justamente por seu autor desejar que seu livro "não fosse de nenhum sexo" (Id., ibid., p. 119). O resultado é uma obra "hermafrodita que não tem nem a energia do homem, nem a languidez da mulher" (Id., ibid., p. 119). Retomando em tom de eufemismo as piadas que circulavam sobre Thomas, Diderot explica que este "pensou muito, mas não sentiu o bastante; sua cabeça atormentou-se, mas seu coração permaneceu tranquilo" (Id., ibid.).

Ora, em se tratando daquelas que são, ao mesmo tempo, "belas como os serafins de Klopstock, terríveis como os diabos de Milton" (Id., ibid., p. 120), não é exatamente esse o melhor método de abordagem. Como explica Elisabeth Badinter, aqui, "a dissertação não é adequada, e o rigor filosófico deve dar lugar ao sentimento, e até mesmo, por que não, ao delírio" (Badinter, 1991, p. 
25-26). Assim, o que se observa no estilo da "resposta" de Diderot ao Ensaio de Thomas é uma proximidade com o tema e uma originalidade que se chocam com os padrões sugeridos por qualquer Academia - sendo que, ao mesmo tempo, estão inteiramente em acordo com o movimento do pensamento "disparatado e centrífugo" (Fontenay, apud Souza, 2002, p. 15) do filósofo. Dito de outro modo, para retomar as palavras de Badinter, Diderot "preferiu falar das mulheres como amante", argumentando que, neste caso, a ausência do desejo pode ser prejudicial à objetividade (Badinter, 1991, p. 26).

Como se sabe, a ideia principal do comentário de Diderot é a de que nós, mulheres, somos governadas pelo órgão que trazemos dentro, que nos causa "terríveis espasmos" e estimulam nossa imaginação "fantasmas de todo tipo". Sim, trata-se do útero, "próprio do [seu] sexo", e é o "delírio histérico" que conduz as mulheres ao passado ou ao futuro, fazendo com que "todas as épocas" lhes sejam presentes e que elas experimentem, quase simultaneamente, sentimentos celestiais ou infernais (Diderot, apud Badinter, 1991, p. 121). Claramente, estamos diante de uma concepção da natureza humana em que a estrutura orgânica indica os caminhos a serem tomados pela ética e pela sociabilidade, e na qual "a virtude ou a sabedoria (sagesse) consiste num estado de equilíbrio entre os principais centros de atividade do organismo humano, que são a sensibilidade e a reflexão" (Souza, 2002, p. 21). Não é fácil vislumbrar as mulheres atingindo esse estado, sendo que vivem sob a égide de uma força "natural" absolutamente avassaladora.

Isto posto, interessa aqui observar, de um lado, de que modo tal concepção da mulher se configura no célebre episódio de Madame de la Pommeraye, em Jacques le fataliste; e, de outro, estabelecer possíveis correspondências entre as mulheres personagens desta narrativa-digressão com as personagens femininas do romance inglês Love in Excess. A Fatal Inquiry, de Eliza Haywood, publicado em Londres em 1719. O intuito é aproximar França e Inglaterra, sugerindo um movimento que ecoa, em certa medi- 
da, uma faceta importante dos diversos interesses intelectuais de Diderot. Que conceitos a respeito da ética e do corpo femininos se revelam nessas duas histórias? Em que medida as personagens femininas se tornam configurações destes conceitos? Que tipo de savoir-faire é revelado nas narrativas de Diderot e Haywood? Que papel têm estas mulheres e seu savoir-faire no desenvolvimento das tramas?

O mote para esta aproximação é oferecido pelo próprio Diderot, ainda em seu breve comentário a respeito do Ensaio de Thomas. Diz ele:

[As mulheres] são impenetráveis na dissimulação, cruéis na vingança, constantes em seus projetos, sem escrúpulos com relação aos meios para ter sucesso, armadas de um ódio profundo e secreto contra o despotismo do homem, parece que há entre elas uma conspiração tácita de domínio, uma espécie de liga, tal como aquela que subsiste entre os sacerdotes de todas as nações; dela conhecem os artigos, sem que se tenham comunicado a respeito. Naturalmente curiosas, querem saber, seja para usar, seja para abusar de tudo [...]. Aquele que as desmascara é seu implacável inimigo. Se as amais, elas vos perderão; perderão a si próprias se obstruirdes seus propósitos ambiciosos. (Diderot, apud Badinter, 1991, p. 121).

É através da ideia de uma possível "conspiração tácita de domínio" caracterizada pela dissimulação e pela vingança, pela falta de escrúpulos e pelo recalque, que se pode retornar às figuras femininas no episódio de Mme. de la Pommeraye e no romance de Eliza Haywood. Aproveitando o clin d'oeil de Michel Delon em seu Le Savoir-vivre libertin, parece mais proveitoso, ao invés de analisar uma ou outra personagem em particular, tomá-las em conjunto, procurando reconstruir o papel destes grupos (conspiratórios?) de mulheres na organização das intrigas. Neste sentido, talvez se possa, de fato, vislumbrar uma espécie de "feminismo" avant la lettre dentro do qual a libertinagem tem lugar de desta- 
que. ${ }^{1}$ Diga-se de passagem, o termo "intriga" assume facilmente dois sentidos nesse contexto: tanto como a trama ou o enredo propriamente dito dessas narrativas, quanto como "armação", engano ou armadilha - ingredientes centrais nas duas histórias. Passemos aos detalhes.

A história de Madame de la Pommeraye é uma entre as várias digressões que o narrador se permite enquanto conduz seus leitores pela jornada de Jacques e seu amo. Quem relata a história da vingativa senhora, no entanto, é a "hôtesse", proprietária, junto com o marido, de uma estalagem em que se encontravam os dois viajantes. Não que tenha sido fácil para ela tomar a palavra: é interrompida inúmeras vezes, não somente pela impertinência de Jacques - "Senhor Jacques, o senhor está me interrompendo!"-, mas por inúmeras outras demandas que dizem respeito a seu trabalho na hospedaria (“Já vou, já vou”’). A estalajadeira narra, portanto, apesar de todos os percalços iniciais. O narrador a descreve como "a elegante, prolixa e faladeira proprietária" 4 "uma mulher grande e repleta, ágil, com boa cara, encorpada, [...] a fisionomia aberta e alegre, um busto para se enlear durante uns dois dias, $[\ldots]$ as mãos soberbas, mãos para serem pintadas ou modeladas".

Além disso, depois de uma longa interrupção, ela retorna com duas garrafas de vinho de champanhe para terminar a história que havia começado a contar. Com tantas qualidades e bons argumentos, a "hôtesse" se torna a primeira mulher importante nessa "conspiração" feminina que começa a se configurar. Isto porque ela não se resume a entreter e agradar, mas também porque toma posição, no melhor estilo do diálogo praticado por

1 Cf. Delon, 2000, p. 294.

2 "Monsieur Jacques, vous m'interrompez!" (Diderot, 1983, p. 125).

3 "I'y vais, i'y vais" (Id., ibid., p. 127).

4 "élégante et prolixe bavarde d'hôtesse" (Id., ibid., p. 132).

5 "une femme grande et replète, ingambe, de bonne mine, pleine d'embonpoint, [...] la physionomie ouverte et gaie, une poitrine à s'y rouler pendant deux jours, [...] les mains superbes, des mains à peindre ou à modeler" (Id., ibid., p. 139). 
Diderot, a respeito das diferenças de condição entre homens e mulheres, especialmente no tocante à desigualdade entre os dois sexos em relação ao amor: "Veja só, meu senhor, somente as mulheres sabem amar, os homens não entendem nada disso..." ${ }^{6}$, ou ainda, "Oh! como nós somos bobas !" .?

A segunda figura feminina no centro da trama é, evidentemente, Madame de la Pommeraye em pessoa, "uma viúva que tinha educação, berço, fortuna e grandeza” ${ }^{8}$ Resistiu alguns meses aos avanços do marquês des Arcis e acabou cedendo, para confirmar, depois de algum tempo, que não era mais amada. A partir desse momento, Madame de la Pommeraye coloca a narrativa em marcha através de um terrível plano de vingança. Como explica a narradora, "ela pensou em se vingar, mas se vingar de uma maneira cruel, de uma maneira que assustasse todos que fossem tentados, no futuro, a seduzir e enganar uma mulher de bem". ${ }^{9}$ Para auxiliá-la na tarefa, a amante magoada contrata Madame e Mademoiselle Duquênoi, mãe e filha originárias da província e cuja ruína havia conduzido a "tenir tripot", ou seja, a manter uma casa de jogo clandestina (e outras coisas mais) em Paris sob o nome de d'Aisnon.

Está formado, assim, o quarteto que organiza a narrativa cujo objetivo final é a desgraça do marquês através de seu casamento com mademoiselle, socialmente inferior a ele e com um passado no mínimo condenável aos olhos do monde. No cerne do projeto - para a revolta de Jacques ("A sua Madame de la Pommeraye é uma malvada” ${ }^{10}$-, estão o desejo frustrado, a ganância, a vingan-

6 “Tenez, monsieur, il n'y a que les femmes qui sachent aimer, les hommes n'y entendent rien..." (Id., ibid., p. 126).

7 "Oh! que nous sommes sottes!" (Id., ibid., p. 142).

8 "une veuve qui avait des mœers, de la naissance, de la fortune et de la hauteur" (Id., ibid., p. 125-126).

9 "elle songea à se venger, mais à se venger d'une manière cruelle, d'une manière à effrayer tous ceux qui seraient tentés à l'avenir de séduire et de tromper une honnête femme" (Id., ibid., p. 142).

10 "Votre Madame de la Pommeraye est une méchante femme" (Id., ibid., p. 167). 
ça. Como engrenagem, aparecem o artifício e a sedução, num encenado jogo de aparências e palavras que envolvem rapidamente des Arcis, "um homem de prazer" que conhece bem "a inconstância do coração humano, [...] a frivolidade dos juramentos". ${ }^{.1}$ Ironicamente, ele se deixa levar pela artimanha mais vil. Neste processo de manipulação do marquês, Madame de la Pommeraye demonstra um controle exemplar dos ritmos da narrativa, conduzindo de modo magistral, gradualmente, o vaivém de suas comparsas e as expectativas da vítima. A vingança à la française parecia, de fato, perfeita.

Do outro lado do Canal, ainda em 1719, Eliza Haywood, née Fowler, publicava seu primeiro romance, Love in Excess. A Fatal Inquiry. A figura de Haywood mereceria algumas páginas de atenção: atriz e dramaturga, periodista, crítica literária, romancista e tradutora, ela viveu de seus escritos - e de encenações teatrais durante os 37 anos que duraram sua carreira, sem mencionar seu envolvimento cada vez mais intenso com a vida política inglesa a partir da década de 1730. O casamento precoce com o Haywood que lhe deu o nome não durou muito. Eliza preferiu escolher seus parceiros e preservar sua independência - o que não era exatamente um comportamento recorrente na Londres do início do século XVIII e que, aliás, continua raro em alguns rincões deste nosso mundo. Como se não bastasse, seu primeiro romance lhe rendeu bons frutos: encabeçou a lista dos livros mais vendidos até ser alcançado por Gulliver's Travels (1726), de Jonathan Swift e, mais tarde, por Pamela (1740), de Samuel Richardson.

Pode-se argumentar, com certa razão, que Diderot e Eliza Haywood pouco têm em comum, tendo em vista que não pertencem exatamente à mesma geração (Haywood morreu em 1756) e nem, em última instância, ao mesmo mundo. Porém, as trocas

11 "un homme de plaisir [...] ; l'inconstance du cœur humain, [...] la frivolité des serments" (Id., ibid., p. 132). 
culturais entre os dois lados da Mancha ocorreram em vários níveis, com mediação e ritmo sugeridos pelas contingências que se impuseram, ao longo dos anos, nas relações entre os dois países. É neste âmbito mais amplo que interessa aproximar a história de Madame de la Pommeraye e Love in Excess, romance que se pautou, em larga medida, pelos chamados romans de femmes célebres na França já no início do século ${ }^{12}$. Além do mais, a narrativa de Haywood apresenta uma semelhança nada irrelevante em relação à história de Diderot: trata-se, como no caso francês, de uma intriga de vingança em que um só homem se encontra literalmente cercado por uma trupe de quatro mulheres.

O felizardo chama-se conde d'Elmont, já que a história se passa na Paris aristocrática imaginada à moda inglesa, apelo comercial certeiro. O conde faz a unanimidade da sociedade parisiense, pois "a Beleza de sua Pessoa, sua Jovialidade, e os Charmes únicos de sua Conversação, tornavam-no admirado pelos dois Sexos". ${ }^{33}$ Aloisa, jovem, nobre, rica e órfã contrai prontamente uma paixão violenta pelo conde. Infelizmente, ela não é correspondida e, diante de tanta indiferença, a moça só "suspirava, queimava, se enfurecia [...]". ${ }^{14}$ Até que um dia, o "Amor (engenhoso em Invenção) a inspirou com uma [resolução] que poderia ajudá-la a conhecer os Segredos do Coração dele, sem a Vergonha de revelar os seus próprios". 15

Ela envia-lhe uma carta anônima declarando-se uma "vítima" do poder do conde no âmbito amoroso - "Irresistível como você é na guerra, é ainda mais no Amor: Aqui, você conquista sem um só Ataque, e nós nos Rendemos antes de você Intimar

12 Ver, a este respeito, Mariette-Clott \& Zanone, 2012.

13 "the beauty of his Person, the Gayity of his Air, and the unequal'd Charms of his Conversation" (Haywood, 1722, p. 1).

14 "she sigh'd, she burn'd, she rag'd" (Id., ibid., p. 2).

15 "Love (ingenious in Invention) inspir'd her with one, which probably might let her into the Secrets of his Heart, without the Shame of revealing her own." (Id., ibid., p. 3). 
$[\ldots] "{ }^{16}$ D'Elmont, de início pouco interessado no assunto, começa a sentir certa simpatia pela ideia de ter uma amante - podia ser divertido e, além de tudo, estava na moda. Acontece que, em vez de imaginar ser Aloisa a autora da carta, ele escolhe cortejar Amena, uma linda mocinha muito mais dócil do que sua verdadeira admiradora. Incansável e mais rica do que Amena, Aloisa consegue se casar com o conde, mas, mesmo assim, a narrativa se ocupa, essencialmente, das voltas e reviravoltas das intrigas que a vingativa Aloisa coloca em marcha para afastar o marido de possíveis rivais. Para complicar ainda mais as coisas, o conde acaba desenvolvendo intensa paixão por Melliora, a filha de seu antigo preceptor, enquanto Mellantha (irmã espevitada de seu melhor amigo) faz de tudo para se encontrar a sós com ele entre quatro paredes. Entre as lamúrias de Amena - que acaba confinada num convento -, as palpitações de Melliora, os avanços sexuais de Mellantha e a vingança implacável de Aloisa, sobre pouco tempo para que D'Elmont se dedique a qualquer outra atividade.

De todo modo, trata-se de um romance em que as mulheres expressam abertamente seu desejo e procuram satisfazê-lo. Como indica certeiramente April Alliston, o romance de Eliza Haywood é um livro sobre “o desejo transgressor [...]. A tensão que alimenta o enredo, tal como acontece em muitas outras obras, é a do desejo e da proibição; neste caso, porém, o campo de batalha entre as duas forças é uma determinada ideia de feminilidade, o que [...] no século XVIII era chamado de 'caráter feminino' " (Alliston, 2009, p. 778). E o que isto significa, dentro do universo do romance inglês? As convenções do gênero "implicavam [...] a ideia de que as mulheres eram vítimas de desejos sexuais violentos e irrefreáveis, sendo demasiado fracas mental, moral e fisicamente para controlar as paixões, ao contrário dos homens [...]" (Id., ibid., making an Attack, and we Surrender before you Summons." (Id., ibid., p. 3). 
778). Ainda de acordo com Alliston, Haywood havia herdado uma certa ideia de amor presente nas obras das romancistas francesas setecentistas que ela lia e traduzia, uma ideia segundo a qual o amor seria uma

forma de desejo heterossexual que se pode combater com maior ou menor êxito (sob a condição, porém, de se exercer uma grande violência contra si próprio), mas que em última instância transcende o controle do indivíduo e subjuga o corpo (com rubores, desmaios e todos aqueles sinais involuntários que, no decorrer do século, serão considerados sintomas de 'sensibilidade') e o inconsciente (com sonhos, delírios, desfalecimentos). Nesse sentido, o 'amor' de Eliza Haywood antecipa o conceito freudiano das pulsões libidinais, que devem ser reprimidas, mesmo retornando continuamente; e sempre nesse sentido, o desejo despertado pelo amor é 'fatal', nas duas acepções que a palavra carregava no século XVIII: 'mortal', mas também 'atuante com a força da fatalidade', pois capaz de guiar as ações dos personagens e decidir seus destinos. (Id., ibid., p. 779).

As paixões de Aloisa, assim como aquelas de Madame de la Pommeraye, são marcadas por uma constância inabalável que, associada a uma extrema sutileza de artifício, atribuem às duas mulheres papel fundamental nas duas narrativas; são elas que costuram e descosturam as tramas. Porém, sem a participação das Duquênoi (mãe e filha) ou de Amena, Melliora e Mellantha, as intrigas não teriam o mesmo impacto na medida em que, em ambos os casos, o desejo é acompanhado de uma paixão quase tão fatal: a curiosidade. ${ }^{17}$ As fantasias de des Arcis e de d'Elmont a respeito de todas essas mulheres são ingrediente central no desenrolar das intrigas e tais fantasias têm sua origem num savoir-faire feminino que anuncia (ou retoma) elementos fortes do universo da 
libertinagem. Os corpos das mulheres, plenamente investidos nas peripécias amorosas, pressupõe uma ética que, entre outras coisas, alerta para os perigos de se "ignorar as necessidades sexuais"18, de se reprimir as pulsões.

Neste sentido, a concepção do feminino indicada no excerto do comentário de Diderot a respeito do Ensaio de Thomas não entra em contradição com o que o leitor (ou a leitora) encontrava tanto na história de Madame de la Pommeraye quanto em Love in Excess, apesar das diferenças entre os dois textos. Numa espécie de conluio feminista (no caso das personagens de Haywood, involuntário), estas personagens engajam seus sentidos e seu espírito numa investigação quase calculista a respeito do amor e dos sentimentos correlatos, como o ciúmes e a vingança, a mágoa e o interesse. Neste jogo, suas principais cobaias também são os seus objetos de desejo.

No entanto, o desfecho, nos dois casos, é bem pouco vantajoso para as duas mulheres cujos sentimentos e ações servem de motor das intrigas: Madame de la Pommeraye amarga o casamento feliz do marquês des Arcis com a filha de Madame Duquênoi, enquanto Aloisa acaba morrendo acidentalmente, ferida pela espada de D'Elmont. Castigo? Fato é que, tanto na Inglaterra quanto na França, é a hostilidade à figura da mulher inteligente (e ardilosa?) que se imporá de maneira cada vez mais intensa ao longo do século XVIII e, certamente, durante o século XIX. Do lado francês, só cresceu, neste período, a força da ideologia rousseauniana que negava às mulheres "o saber e a glória" e sugeria a elas que ficassem trancadas em casa, ou num convento (Badinter, 1991, p. 13). Do lado inglês, é também um outro modelo de feminilidade que ganha progressivamente mais terreno, com a rejeição, por parte da novel, da "tradição internacional e femininocêntrica a que Eliza Haywood pertenceu" em prol "da autarquia vitoriana” 
(Moretti, apud Alliston, 2009, p. 783). A bela Melliora e a jovem Madame des Arcis - mocinhas arrependidas, virtuosas e contritas -, parceiras de Pâmela, sobraram para nos contar a nossa história.

\section{Referências bibliográficas}

ALLISTON, A. “Amor em Excesso. Eliza Haywood (1719-20)”. In: MORETTI, Franco (Org.). A cultura do romance. São Paulo: Cosac Naify, 2009. p. 777-785.

BACKSCHEIDER, P. R. (Ed). Selection Fiction and Drama of Eliza Haywood. Oxford: Oxford University Press, 1999. ; INGRASSIA, C. Eighteenth-Century English Novel and Culture. London: Blackwell Publishing, 2005.

BADINTER, E. O que é uma Mulher? Rio de Janeiro: Nova Fronteira, 1991.

CRU, R. Loyalty. Diderot as a Disciple of English Thought. New York: Columbia University Press; Kessinger Publishing, 1913. DELON, M. (Dir). Dictionnaire européen des Lumières. Paris: Quadrige; PUF, 2010. Le Savoir-vivre libertin. Paris: Hachette Littératures, 2000.

DIDEROT, D. Jacques le fataliste. Paris: Librairie Générale Française, 1983.

Sur les femmes. Disponível em http://voie-lactee.fr. Acessado em 16/11/2013.

HAYWOOD, E. Love in Excess, or the Fatal Inquiry. London: D. Brown jun., W. Chetwood, and S. Chapman, 1722. Disponível em https://archive.org/details/loveinexcessorfaoohayw.

MARIETTE-CLOT, C.; ZANONE, D. La Tradition des romans de femmes. XVIII ${ }^{e}$-XIXe siècles. Paris: Honoré Champion, 2012. MOWRY, M. "Eliza Haywood's Defense of London's Body Politic”. SEL, 43, p. 645-665, Summer 2003. 
SMIETANSKI, J. Le Réalisme dans Jacques le fataliste. Paris: A. G. Nizet, 1965 .

SOUZA, M. G.. Natureza e Ilustração: sobre o materialismo de Diderot. São Paulo: Unesp, 2002. 